\section{True cervicothoracic meningocele: a rare and benign condition}

Bruno L. Pessoa, Yara Lima, Marco Orsini

Department of Neurosurgery, Universidade Federal Fluminense, Rio de Janeiro; Severino Sombra University Center, Medicine Department, Vassouras, Rio de Janeiro, Brazil

\section{Abstract}

Cervical meningoceles are rare spinal dysraphism, accounting for approximately $7 \%$ of all cystic spinal dysraphism. In spite of the rarity, the clinical course is most of the times benign. The surgical treatment includes resection of the lesion and untethering, when presented. We present a 14-day-old female child with true meningoceles who underwent to surgical excision and dura-mater repair. Retrospect analysis of the literature concerning true cervical meningocele is performed. By reporting this illustrative case, we focus on its classification and its differentiation from other types of cervical spinal dysraphism, such as myelocystocele and myelomeningocele. Although its course is benign, it is mandatory a continuum follow up with periodic magnetic resonance imaging of spinal cord, since late neurological deterioration has been described.

\section{Introduction}

Cervical dysraphism is a very rare condition, performing 3-6\% of all the dysraphism found in children and adults. Still more uncommonly seen, the true cervical meningocele is described in about 7\% of all cervical dysraphism, according to one of the largest series reported. $1-3$

Conceptually, meningoceles are posterior midline malformations that consist in a spina bifida containing dura-mater and arachnoid herniated and revealing cerebrospinal fluid as content. More often, the skin adjacent is not disrupted and might be pedunculated. As general rule, no neural contents are tethered to any neural plaque, although some nerves might fluctuate in the cerebrospinal fluid. This last aspect in particular differentiates meningoceles from myelomeningoceles. ${ }^{2,4}$

Mostly seen in the lumbosacral area, meningoceles are uncommon at the cervical region. Despite its infrequent association with other spinal malformations, late neurological deterioration has been described, justifying the necessity of a long-term follow up. ${ }^{2}$

Although some cases of cervical dysraphism have been described in the literature, a true meningocele has rarely been seen. One report a single case of true cervical meningocele operated on, with its clinical and surgical details. Additionally, its neurological status up to now is related. Finally, a review of literature is done, stressing the differences between true meningocele and other forms of cervical dysraphism.

\section{Case Report}

\section{Presentation and examination}

A 14-days-old female child was born at term with a caesarian delivery in 2011. During the pregnancy some complications occurred, such as tract urinary infection and oligohydramnios, without premature rupture of membranes.

Physical examination revealed a posterior cervical mass well circumscribed and with normal skin covering, measuring $3 \mathrm{~cm}$ in width, 3.5 $\mathrm{cm}$ in height and $4 \mathrm{~cm}$ in length in the superior cervical midline at birth (Figure 1). The lesion was covered with normal skin. No signs of cerebrospinal fluid (CSF) leak were noted. She had no neurological deficits and the neurological examination was normal, with head circumference measuring $34.5 \mathrm{~cm}$ at that point.

Routine hematological and biochemical tests were normal. Yet, a chest radiograph showed no abnormality.

\section{Radiologic aspects}

The patient underwent computed tomography (CT) scan of the cervical spine, which demonstrated multiple defects in fusion of the posterior arches of cervical vertebrae. Those aspects were found at or close the base of the meningocele, in the level of $\mathrm{C} 3$-C7. In addition, the CT scan of the head revealed hydrocephalus.

Magnetic resonance imaging (MRI) of neuro-axis was performed only in the postoperatively segment and showed hydrocephalus. No further significant alterations were observed.

\section{Surgical findings}

The surgical repair of the meningocele occurred on day 5 and no complications were observed. The mass was resected under general anesthesia and prone position. Prophylactic antibiotic was applied and proper positioning, taking care with possible compression injuries. An elliptical standard incision was made around the lesion. In an easy way, we
Correspondence: Marco Orsini, Department of Neurosurgery, Universidade Federal Fluminense, 95 Tavares de Macedo street, 902 Niterói, RJ, ZIP 24220-211 Brazil.

E-mail: orsinimarco@hotmail.com

Key words: Cervical meningocele; spinal dysraphism.

Contributions: the authors contributed equally.

Conflict of interest: the authors declare no potential conflict of interest.

Received for publication: 14 June 2015. Revision received: 14 September 2015. Accepted for publication: 7 October 2015

This work is licensed under a Creative Commons Attribution NonCommercial 3.0 License (CC BYNC 3.0).

(C) Copyright B.L. Pessoa et al., 2015

Licensee PAGEPress, Italy

Neurology International 2015; 7:6079

doi:10.4081/ni.2015.6079

found an interface between dura-mater plane and the subcutaneous/muscular tissue. The standard microsurgical techniques were applied. A cystic and translucent mass was observed and opened (Figure 2).

A posterior fusion defect at the $\mathrm{C} 3-\mathrm{C} 4, \mathrm{C} 4$ C5, C5-C6 and C6-C7 interspaces were noted. A normal cord was seen and carefully intradural inspection was made, searching for any bands or adherences that could be tethering the spine cord. No tethering at this point was visualized, but arachnoid bands were removed. Besides, the cyst's wall and the redundant dura-mater were resected as well. A simple dura reconstruction was performed and the paraspinal muscles were closed in a single layer. She was discharged on the 7th postoperative day. Neither neural elements nor stalks were seen inside the mass, which led us classify it as a true meningocele according the study performed by Salomão et al. ${ }^{1}$

\section{Postoperative course}

Postoperatively, her neurologic examination remained normal and she had a good recovery. During the outpatient follow up, her head circumference increased to $42.0 \mathrm{~cm}$. She underwent a neuroaxis MRI on the 30th postoperative day, which showed increase of the hydrocephalus (Figure 3). Two days later, a VP shunt, according to standard techniques, was performed. No complications occurred during both the procedures and the patient had no additional deficits. At the time that this paper has been written, she was doing very well and no neurological complications have been seen. 


\section{Discussion}

Although cystic spinal dysraphism is a wellknown condition, it remains rare, accounting for only 1-5 \% of all neural tube defects.5-8 Despite the majority of the cases being described in children, there are few reports in adults.7,9

In one of the earliest series described from this topic, Pang et al. reported 9 cases of cervical myelomeningocele. None of them were characterized as true meningoceles. As they stated, there were narrow stalks of similar tissues within the thecal sac and all nine ones therefore contained some central neural tissues. In spite of those findings, they reported good neurological results even in late outcomes. ${ }^{3}$

In the biggest series published so far, Salomao et al. retrospectively studied 18 cases with cystic spinal dysraphism and only one of them was a true cervical meningocele, whereas neither hydrocephalus nor Chiari malformation were found. Besides, the neurologic exam was normal. All patients from their series underwent surgical exploration. ${ }^{1}$

In a retrospective study, Mostafa et al. published 8 cases of cystic spinal dysraphism and 2 of them could be characterized as true cervical meningocele. Except for 1 case, whereas lumbosacral myelomeningocele (double meningocele) coexisted, in all cases the neurological exam was normal. Two patients had hydromyelia; 2 had Chiari malformation and 4 had hydrocephalus. All cases underwent surgical treatment and the outcome after surgery was excellent as well. ${ }^{10}$

In the same way, Delashaw et al., in 1987, described 2 cases of true cervical meningocele. 4 As they stated, the hydrocephalus are not always the greatest concern in these conditions. Many others problems may play a role in neurological deterioration, such as hydromyelia, diastematomyelia and lipomeningomyelocele with tethered spinal cord, justifying a continuum follow up of these patients. However, they did not describe any differences regarding true meningoceles and classical ones. 4

In 2001, Nishio et al. reported 2 cases of cervical meningocele. One out of them represented a true meningocele. No neurological deficits were found. Indeed, no associated anomalies were related. In that case, the patient underwent clinical follow up and no surgical treatment was performed. 11

In a similar paper, Orakdogen et al., in 2009 described 7 cases of spinal dysraphisms of the cervicothoracic region in childhood, whereas only 1 case was configured as true meningocele. In 3 out of 7 cases other associated anomalies, such as SCM type 2, Chiari type 2, hydrocephalus and hydromyelia occurred. All cases underwent surgical treatment, with excision of the sac and untethering of the spinal cord, when presented. In this paper, the authors also pointed out the more favorable outcome of that condition when compared to lumbar counterparts. ${ }^{12}$ Although no long-term follow up has been described for this author, the benign course of this condition may give support to that decision-making. No author has reported any series consisting of three or more cases of the true cervical meningocele, until now.

In this particular, in the literature review, we found hydrocephalus in 4 out of 9 cases, required a ventriculoperitoneal (VP) shunt (as our case, mentioned above). Furthermore, 2 patients were shown with Chiari malformation, but no reports of posterior fossa craniotomy were reported as necessary. All patients were children although some adults' cases had been reported in other kinds of spine cystic dysraphism. The median age of 7 months (range 2 weeks - 8 years) was found and the male to female rate was $4: 6$. In most of the cases, the neurological examination was nor-

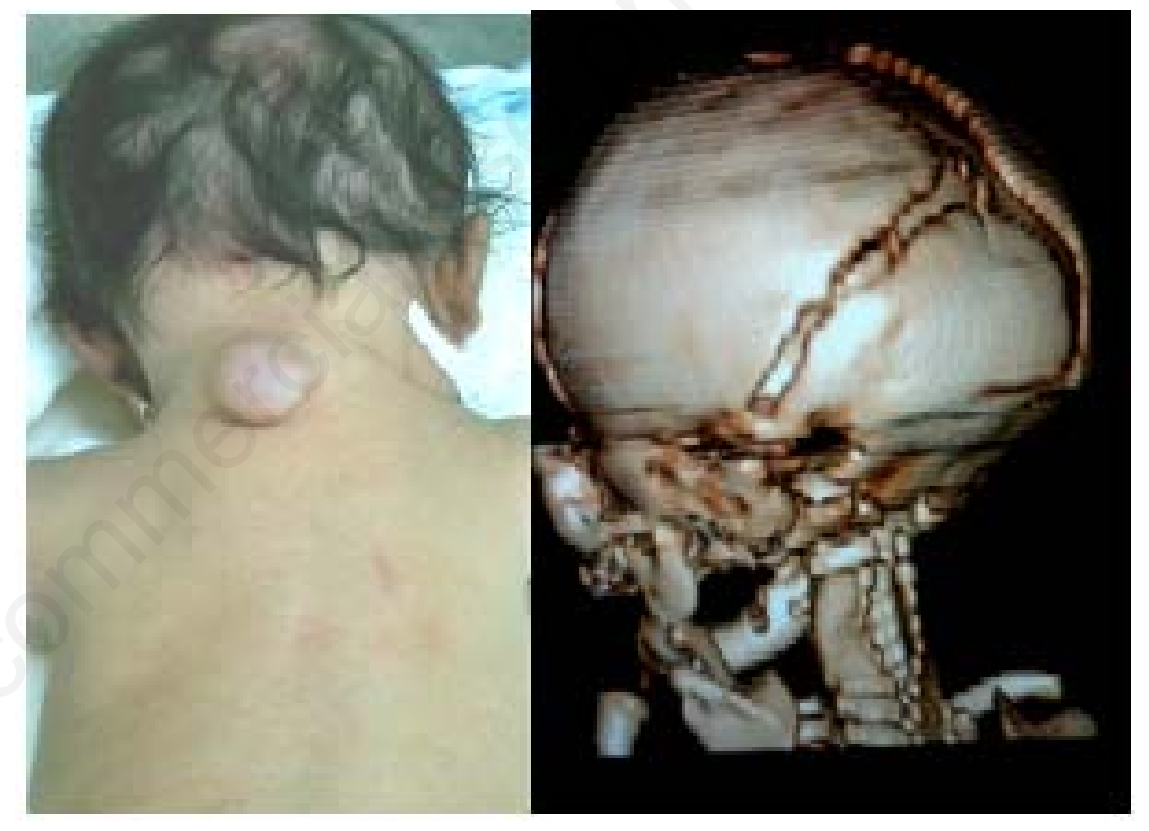

Figure 1. A small posterior cervical meningocele with a thicker skin and the correspondent preoperative 3D computed tomography scan, showing laminar defects near the neck of the meningocele.

Table 1. Summary of all published case reports of true cervico-thoracic meningoceles.

\begin{tabular}{|c|c|c|c|c|c|c|}
\hline Author & Age, sex & Lesion location & Neurologic exam & Hydrocephalus & Chiari malformation & Treatment \\
\hline Delashaw et al. ${ }^{4}$ & $29 \mathrm{~m}, \mathrm{~F}$ & C4-C5 & Normal & Yes & No & Excision and VP shunt \\
\hline Delashaw et al. ${ }^{4}$ & $9 \mathrm{w}, \mathrm{F}$ & $\mathrm{C} 7-\mathrm{Tl}$ & Hiperflexia in limbs & Yes & Yes & Excision and VP shunt \\
\hline Nishio et al. ${ }^{11}$ & NR & $\mathrm{Cl}-\mathrm{C} 2$ & Normal & $\mathrm{Nr}$ & No & No treatment \\
\hline Meyer-Heim et al. ${ }^{13}$ & NR & $\mathrm{Cl}-\mathrm{C} 2$ & Normal & No & No & Excision \\
\hline Salomão et al. ${ }^{1}$ & $2 \mathrm{w}, \mathrm{F}$ & T6-T7 & Normal & No & No & Excision \\
\hline Orakdogen et al. 12 & $7 \mathrm{~m}, \mathrm{M}$ & T3-T4 & Normal & Yes & Yes & Excision and VP shunt \\
\hline Mostafa et al. ${ }^{10}$ & $8 \mathrm{y}, \mathrm{M}$ & NR & Paraplegia & No & No & Excision \\
\hline Mostafa et al. ${ }^{10}$ & $8 \mathrm{~m}, \mathrm{M}$ & NR & Normal & No & No & Excision and unthetering \\
\hline Pessoa et al. & $2 \mathrm{w}, \mathrm{F}$ & $\mathrm{C} 3-\mathrm{C} 7$ & Normal & Yes & No & Excision and VP shunt \\
\hline
\end{tabular}

$\mathrm{NR}$, not reported; m, months; w, weeks; y, years; VP, ventriculoperitoneal. 
mal, except in 2 cases.1,4,10-13 Table 1 summarizes some data from case reports.

Many different denominations have been used to classify the spina bifida cystica, such as cervical myelomeningoceles, cervical meningoceles, rudimentary meningocele, myelocystocele, etc. ${ }^{3,4,14-16}$

In spite of controversy classification of these lesions, Salomão et al. classified cystic spinal dysraphism in three categories based on the structures found inside the cyst: type I (stalks), type II (myelocystoceles) and type III (true meningoceles). In type I, a fibrovascular or neuroglial tissue protruding from posterior surface of spinal cord attach to the sac wall. Type II presents an ependymal-lined cyst that herniates inside of a meningocele, representing a hydromyelic canal in connection with an outer cyst. Finally, in type III, meaningeal tissue herniates through the defect and the sac contains only CSF. No neural elements are found inside the cyst and only arachnoid bands may tether the spinal cord. ${ }^{1}$

Since the spinal cord is within the spinal canal, one could question whether these lesions should be called myelomeningoceles. In conceptual bases, only the last type of cystic spinal dysraphism represents a true meningocele. ${ }^{1}$

In Salomao et al.'s series, type I was found in $78 \%$, type II in $16 \%$ and type III in $5 \%$ of all cases. These data are according other authors, concerning the prevalence of the different types of lesions in cystic spinal dysraphism. ${ }^{17}$

Thus, in our opinion, the classification of all those lesions as cervical myelomeningoceles or meningoceles is not appropriate anymore. A wide spectrum of different alterations observed inside the lesion does not allow us to use such a simple classification and support the use of Salomao et al.'s classification. ${ }^{1}$

Indeed, these lesions are quite different from thoracolumbar and lumbosacral counterparts. Firstly, lumbosacral lesions are covered by a thin, delicate arachnoid, whereas a full thickness skin at the base and squamous epithelium at the dome always cover the cervical ones, so that CSF leaks are unusual. ${ }^{3}$

Second, the neural content of a lumbosacral lesion is usually a flattened, exposed terminal neural placode floating on the dome of the CSF sac (myeloschisis), whereas the cervical lesion is a nearly closed neural tube except for a narrow midline gap, rather than a terminal placode. ${ }^{3}$ Then, paucity of neurological deficits and a more favorable clinical outcome may be explained by the above-mentioned factors.

Usually, those children have normal neurological development and neurological examination as well. This is in agreement with our review, whereas only 2 cases had any kind of alteration in the neurologic exam. However, in some cases concomitant anomalies may lead to later neurological problems. Such anom-

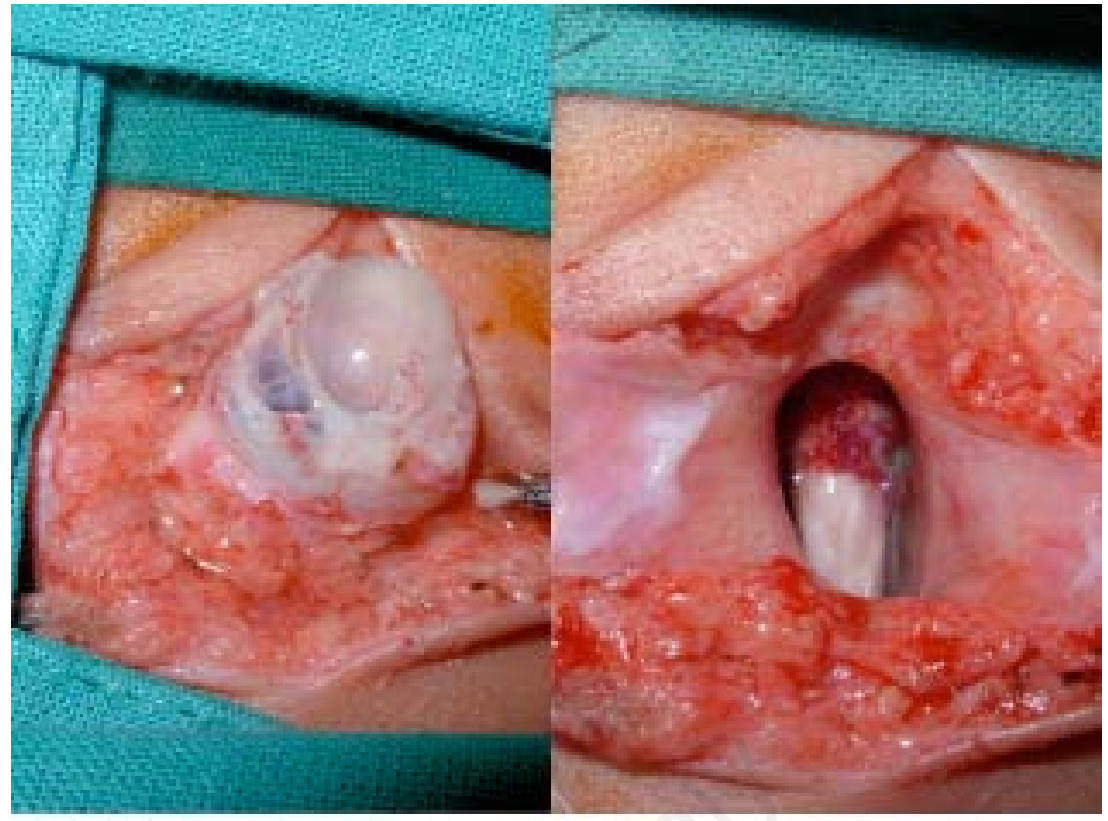

Figure 2. Intraoperative photograph showing a wide pseudocyst formed by arachnoid surface through a midline defect on the dura. On the right side, a normal spinal cord is seen.

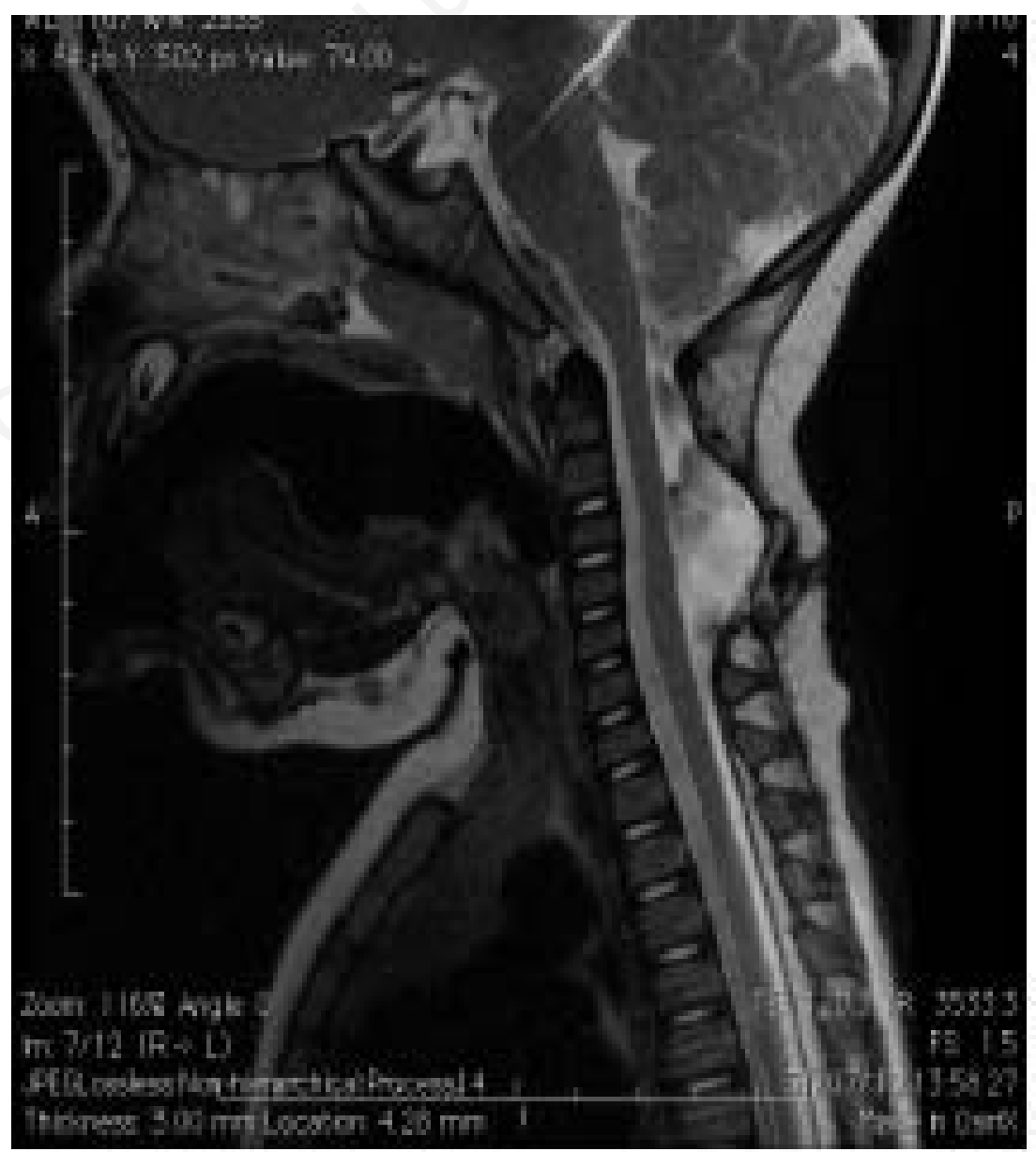

Figure 3. Postoperative cervical sagittal T2-weighted magnetic resonance imaging shows a hyper intense cystic mass, but does not show hydromielia or tethering. 
alies, including hydrocephalus, Chiari malformations, hydromyelia, diastematomyelia, thickened filum terminal and Klippel-Feil syndrome must be recognized, in order to prevent further deterioration or new deficits. 4,18

Moreover, a high percentage of these patients have associated hydrocephalus (4 out of 9 cases). Yet, an expressive number of patients suffer of Chiari malformations (2 out of 9 cases), justifying a continuum strict follow up in clinical setting in those patients.

Differently from thoracolumbar and lumbosacral lesions, surgery in cervical ones have two objectives: prevention of neurological deficit by releasing tethered elements and cosmetic reasons. Surgical excision of the meningocele as well intradural exploration to untether the spinal cord is extremely necessary to prevent delayed neurological deterioration. 3,19

The surgical treatment of these lesions is not technical demanding, consisting of excision of cyst and intradural exploration to untether the spine cord, if fixed by a fibrous band. Furthermore, hydrocephalus may coexist and careful management, with VP shunt, is mandatory. ${ }^{17}$

Important to mention also, is that the neurological outcome is usually good after the procedure. However, some children may suffer a late neurological deterioration over the years, having need of a new secondary surgical exploration owing to retethering or failure to treat the lesion during the primary surgery in an appropriate way. That explains why a long follow up is extremely necessary. $1,3,8,20,21$

We should keep in mind that the classification used in this paper is far from a general consensus. Although it would be a tough task to try to unify all the cases described in the literature under the same classification as used by Salomao et al., 1 this has been possible in this paper, since the authors described the surgical particularities and findings in their respective papers.

To date, a paucity of cases of true meningoceles has been described in the literature, to the best of our knowledge. So far, including our case, only 9 cases of true cervical meningocele were reported. However, the right diagnostic work out and treatment of this rare disease are still essential for a good neurological development, allowing a benign course.
Although our review show no practical differences between true myelomeningoceles and the classical ones, the small sample does not allow us to get to any conclusions. Further studies are needed in order to establish the disparities in terms of prognosis, survival and neurological deterioration in both groups.

\section{Conclusions}

True cervical meningocele is a very rare condition. It can be distinguished from other cystics spinal dysraphism by the absence of any fibrovascular, neuroglial or ependymal tissue inside the cyst. Complete excision is the treatment of choice, having very good functional results. However, continuum follow up is mandatory to prevent late neurological deterioration. In this particular, periodic spinal cord MRI plays an important role in this condition.

\section{References}

1. Salomão JF, Cavalheiro S, Matushita H, et al. Cystic spinal dysraphism of the cervical and upper thoracic region. Childs Nerv Syst 2006;22:234-42.

2. Doran PA, Guthkelch A. Studies in spina bifida cystica: I. General survey and reassessment of the problem. J Neurol Neurosurg Psychiatry 1961;24:331.

3. Pang D, Dias MS. Cervical myelomeningoceles. Neurosurgery 1993;33:363-73.

4. Delashaw JB, Park T, Cail WM, Vollmer DG. Cervical meningocele and associated spinal anomalies. Childs Nerv Sys 1987;3:165-9.

5. Denaro L, Padoan A, Manara R, et al. Cervical myelomeningocele in adulthood: case report. Neurosurgery 2008;62:11691171.

6. Habibi Z, Nejat F, Tajik P, et al. Cervical myelomeningocele. Neurosurgery 2006;58:1168-75.

7. Konya D, Dagcinar A, Akakin A, et al. Cervical meningocele causing symptoms in adulthood: case report and review of the literature. J Spinal Disord Tech 2006;19:531.
8. May D, Rilliet B, Berney J. [Cervical meningocele and meningomyelocystocele. Apropos of 4 cases]. Neurochirurgie 1992;38:347. [Article in French]

9. Wang H, Yu W, Zhang Z, et al. Cervical rudimentary meningocele in adulthood. $\mathrm{J}$ Neurosurg Spine 2013;18:1-4.

10. Ali MZ. Cystic spinal dysraphism of the cervical region: experience with eight cases including double cervical and lumbosacral meningoceles. Pediatr Neurosurg 2010;46:29-33.

11. Nishio S, Morioka T, Hikino S, Fukui M. Cervical (myelo) meningocoele: report of 2 cases. J Clin Neurosci 2001;8:586-7.

12. Orakdogen M, Turk CC, Ersahin M, et al. Spinal dysraphisms of the cervicothoracic region in childhood. Turk Neurosurg 2009;19:400-5.

13. Meyer-Heim AD, Klein A, Boltshauser E. Cervical myelomeningocele: follow-up of five patients. Eur J Paediatr Neurol 2003;7:407-12.

14. Bhargava R, Hammond DI, Benzie RJ, et al. Prenatal demonstration of a cervical myelocystocele. Prenat Diagn 1992;12:6539.

15. El Shabrawi-Caelen L, White WL, Soyer HP, et al. Rudimentary meningocele: remnant of a neural tube defect? Arch Dermatol 2001;137:45.

16. Steinbok P, Cochrane DD. The nature of congenital posterior cervical or cervicothoracic midline cutaneous mass lesions. $\mathrm{J}$ Neurosurg 1991;75:206-12.

17. Kasliwal M, Dwarakanath S, Mahapatra A. Cervical meningomyelocele: an institutional experience. Childs Nerv Syst 2007;23:1291-3.

18. Cochrane DD, Haslam RH, Myles ST. Cervical neuroschisis and meningocoele manque in type I (no neck) Klippel-Feil syndrome. Pediatr Neurosurg 1990;16:1748.

19. Steinbok P. Dysraphic lesions of the cervical spinal cord. Neurosurg Clin North Am 1995;6:367.

20. Rawanduzy A, Murali R. Cervical spine diastematomyelia in adulthood. Neurosurgery 1991;28:459-61.

21. Vogter D, Culberson J, Schochet S, et al. High spinal dysrhaphism. Acta Neurochir 1987;84:136-9. 